\title{
Integrating STEMM in Higher Education: a proposed curriculum development framework
}

\section{Lindsey Conner}

College of Education, Psychology and Social Work, Flinders University, Adelaide, Australia.

\begin{abstract}
Educational systems around the world are trying to grapple with the need for experts in science, technology, engineering, mathematics and medicine (STEMM), who have expert knowledge and can work in collaborative teams to find solutions to local and global issues, including the current pandemic related to the Covid-19 outbreak. Employers seek disciplinary experts as well as people who can act as connectors for groups and ideas and who share and communicate them effectively. Integration of the STEMM disciplines within teaching programmes is in its infancy in higher education, but there is recognition for providing extraordinary experiences for learning that develop collaboration and synthesis of divergent ways of thinking, including crossing disciplinary boundaries. A framework is presented for supporting the design of integrated STEMM course work in higher education. It includes authentic, student-centered, evidence-based, inquiry, problem-based learning through situated, immersive and experiential approaches that can support the deliberate development of skills for integrating thinking, problem-solving and for creating humanistic solutions for local and global issues. This framework can be used as a guide for designing new teaching programs that use transdisciplinary approaches for STEMM in higher education. Refinements of the framework can be generated through rigorously evaluating implementation in specific contexts.
\end{abstract}

Keywords: Covid-19, STEMM, transdisciplinary teaching, higher education, employment. 


\section{Introduction}

Working in interdisciplinary teams already occurs in research in higher education, research institutes and government agencies. However, there are only glimpses of this occurring in teaching programmes or course work in higher education, especially where there is a deliberate focus on inter-disciplinary learning. Integrated approaches in higher education can build on inquiry models and problem-based learning developments in the compulsory education sector (e.g. Corrigan et al., 2015; Sniedze-Gregory, 2018). This paper advocates for a STEMM approach for learning programs in higher education to expand on previous advocacy for integrating STEM (e.g. Malcolm \& Feder, 2016).

The importance of science, technology, engineering, mathematics and medicine (STEMM) knowledge and skills could not be more important globally than now. In the current Covid19 situation, STEMM approaches are required using global collaboration for supporting health systems, decisions about personal health, sustaining creating technological and engineering solutions and understanding how science can contribute to solve problems and enhance life experiences. Integrating STEMM knowledge and skills relies heavily on collaboration, evaluation of knowledge and self-reflection for learning (Conner, 2014). Such knowledge and skills have been highlighted as essential for the future workforce with an estimated $75 \%$ of jobs requiring problem-solving, inquiry, critical and creative thinking (World Economic Forum, 2019). These skills have also been identified as being crucial to ensure economic strength, global competitiveness, national security and guardianship of the environment.

While the separate disciplines have served higher education for considerable time, interdisciplinarity is becoming more recognized as providing promising advances to address complex issues such as climate change (Bammer, 2017; Shaman et al., 2013) and to create novel solutions for health. In the current Covid-19 situation, decisions about restricting social interactions at multiple levels must be based on what we know about virus replication, rates of infection, immunity responses, personal hygiene practices, using statistics to convey data, using bioengineering to create vaccines and treatments, using engineering to create or repurpose factories for making products they were not previously designed to make (masks, hand sanitizer, ventilators) and more. Future ways of working will require more localized adapted solutions that leverage off what has been learned globally.

This means that interdisciplinary learning experiences will be more important than ever before, so that students can be immersed in learning experiences that support them to develop critical and creative thinking as well as collaborative and communication skills. Delanty (2001) goes even further and advocates for universities to reappraise what they focus on in terms of developing a new type of citizenship that is responsive to the changing nature of knowledge production and promotes 'the self-transformation of cultures through a critical 
self-engagement with each other' (p. 128) in other words, collaboration and co-operation. Universities can provide learning experiences that support the development of technocratic skills (those that serve society through professions or service) and develop cultural capital (citizens who can take socially responsible action to improve society) (Delanty, 2001). The opportunities for how STEMM can contribute to this agenda, are only limited by our imaginations. If students need STEMM knowledge and skills, and employers are demanding them, how quickly are education systems adjusting to this need? Instead of piecemeal reform, this paper advocates for an integrated approach and provides a framework for helping to develop this reform.

\section{Previous research on integration of STEMM in undergraduate programs}

The Association of American Universities reported on its' work to support the implementation of better teaching and learning in undergraduate programs (Association of American Universities, 2012). This report provides many specific examples of how curriculum is being integrated within STEMM. Further research, as reported by the National Academy of Science, Engineering and Medicine (2018) indicated that there are some promising results of integrating curriculum. These included:

1. Some integrative approaches in STEMM have led to positive learning outcomes e.g. increased critical thinking abilities, higher-order thinking, reasoning and analysis, problem solving, communication, and teamwork.

2. Integrating STEMM content and pedagogies into arts and humanities may improve inter-disciplinary relations, improve scientific and technological literacy, and data analysis used in humanistic inquiry.

3. Where medical students experienced arts and humanities within their program, they increased their communication skills, empathy, resilience, teamwork and, increased their tolerance for uncertainty.

4. Around the world there is an increase in the number of educational institutions that are integrating curriculum.

Research on the integration of mathematics into other disciplines (or data sciences more generally) indicates huge potential promise (Czerniak, 2007). While science and mathematics share common aspects for problem-solving, teaching programs that truly integrate science and mathematics in higher education is rare (Bush \& Cook, 2019). It is more likely that combining the approaches to learning, such as design thinking from engineering with problem-based and inquiry-based learning from the sciences and mathematics and including case studies and simulations from medicine, are worth pursuing in real-world contexts.

It seems that there is more likelihood of coherence, depth and motivation when design-based approaches are combined with problem-solving approaches (Miller \& Krajcik, 2019). 
Therefore it is not just the knowledge from separate disciplines that can be drawn on in an integrated approach, but the approaches to learning used in different disciplines, can be integrated as well to provide knowledge in and for action.

\section{Proposed interdisciplinary STEMM curriculum model}

The framework in Figure 1 is proposed to support the development of teaching and learning through interdisciplinarity in STEMM contexts. In Figure 1, the Prior knowledge dimension implies that faculty and students are aware that students already possess knowledge (both declarative knowledge and knowledge of skills) or know how to find out. This necessitates using teaching methods and creating support materials to help students reveal their emerging understanding. The use of analytic and intuitive thinking can also help manage their learning progressions.

Student support includes providing resources, learning technologies and access to data for continuous improvement. Supporting students to establish clear goals for learning means that students are more likely to invest effort and manage their time effectively, have a positive mindset about their choices and futures, appreciate differences and are committed to serving their communities (Schreiner et al. 2012).

Key pedagogies will be those that actively engage students e.g. design-thinking, problembased or project-based and inquiry approaches to learning that use scenarios and multiple real-world examples or simulations. The importance of problem-based and inquiry approaches is that they enable specific examples to be investigated. When well-supported, these approaches to learning also assist in the development of students' academic judgement in relation to what knowledge is needed and how to undertake their learning (Conner, 2014). Students need to experience opportunities to critique their understanding and to create, curate and communicate, especially new knowledge they create as part of their collaborations.

Some students may have come through more contemporary learning environments where they have experienced inquiry and cross-disciplinary approaches at senior schools (e.g. see ASMS, Ao Tawhiti Unlimited Discovery). However students may need to be enculturated into new ways of thinking about and managing their own learning especially those who expect to be taught through more traditional teaching and learning approaches.

Through providing Authentic contexts for learning, students will gain a range of domain knowledge through using a range of primary and secondary data sources. The knowledge needed will be appropriate to the learning context. Their learning will be situated in projects or solution-focused experiences that value collaboration /teamwork. Therefore the Learning environments can be described as immersive and experiential where contributions are made to real solutions. Faculty roles may need to shift from being the knower to being the enabler. 
The knowledge needed by students will need to be reconsidered as to what is appropriate. This may be threatening for some faculty whose identity is bound with expertise knowledge that may no longer be relevant to real-world situations. Students are also encouraged to consider interactions of components, using data sciences and cause and effect analyses, so crucial to tinkering through iterations for the best possible solutions, while taking account of influences and unintended outcomes.

The challenge with assessment when using integrated approaches, is related to what is designated as important for students to learn. Changes to curriculum can be driven by changes to assessment. Good learning designers start with the end in mind and identify what learning experiences will enable students to demonstrate the desired outcomes. If creative and critical thinking, collaboration and communication skills are desired, then these should be assessed alongside the tangible solutions as being feasible or achievable. Assessments could evaluate: How did students connect disparate sources of knowledge or use a range of skills to solve a problem? Have students taken humanistic or contingent factors into account?

\section{Limitations of the integrating STEMM}

While integrating disciplines has been implemented in some schooling systems for some time (Sniedze-Gregory, 2018), with some exceptions, higher education has been somewhat reticent about taking up more integrated approaches in STEMM. The reasons given for not integrating curriculum relate to: deeply held views by faculty about the value of separate disciplines; the specialist language and technical issues that may be discipline-specific; the availability of resources for teaching using appropriate pedagogies; faculty backgrounds (especially related to how they were taught or learning within their discipline) and an unwillingness to change; time to conceptualize an integrated approach to teaching and learning; and the need to stay productively researching (Malcolm \& Feder, 2016).

Students also come to higher education with expectations about what and how they will be taught, often based on reputations and traditions. Institutional strategies for improved instruction and co-curricular support have yielded improvements in students' outcomes. It seems that assessment, course sequences, learning environments, student support and students' self-efficacy, all affect student engagement and progression (Malcolm \& Feder, 2016). With the current accelerated shift to teaching in higher education to online environments, considerations of what interaction involves (students with resources, students with faculty and students-students) is of high interest. Students do not necessarily have the requisite self-directed or self-regulating skills sufficient to support their progress (Conner, 2014). 


\section{Conclusion and Recommendations}

This paper is proposing a model to support the development of inter-disciplinarity in STEMM course work in higher education. If designed well, such interdisciplinary approaches can build capability and capacity amongst graduates to solve local and global issues through enacting their knowledge and skills collaboratively. Students will need to be provided with learning experiences for developing skills in design-thinking, problem-solving and interdisciplinary inquiry. They can also benefit from collaborating as emerging, enquiring experts who are ever curious about alternative possibilities and who effectively communicate their new knowledge and potential solutions. This can be a way (as well as research) for universities to generate new knowledge.

Currently most universities around the world are not addressing the need to develop interdisciplinary approaches seriously. Instead there are fragmented interdisciplinary approaches rather than seeking approaches that include iterative changes, reflection, evaluation, synthesis collaboration and authentic assessment. The model proposed in Figure 1 can support this development and the author welcomes feedback on it.

The implications of the proposed framework (Figure 1) is that there may need to be cultural changes for faculty and students to learn within student-centered, active learning pedagogical approaches that use relevant or authentic assessments. There will need to be a shift from delivering factoids to designing rich learning experiences using real-world challenges that require connecting ideas and conceptual mastery as well as developing the skills of collaboration, critical and creative thinking and effective communication. This shift implies that institutions will support staff to rethink how they provide learning experiences, rather than what content they teach. Staff development should be systematic and iterative, where reflection on progress towards effective active learning occurs and is celebrated and rewarded through promotion systems.

Global challenges such as climate change and pandemics, call for working across disciplines that transcend disciplinary silos (Honeybun-Arnolda \& Obermeister, 2019). The integration of disciplines can support development and innovation for a more systems-based generative approach to learning in higher education for a more humanistic future. Further research is warranted to investigate how integration of curriculum through a range of pedagogical approaches within STEMM can prepare students for dealing with complex situations that call for evidence-based and humanistic solutions as they negotiate their worlds as workers and citizens. 


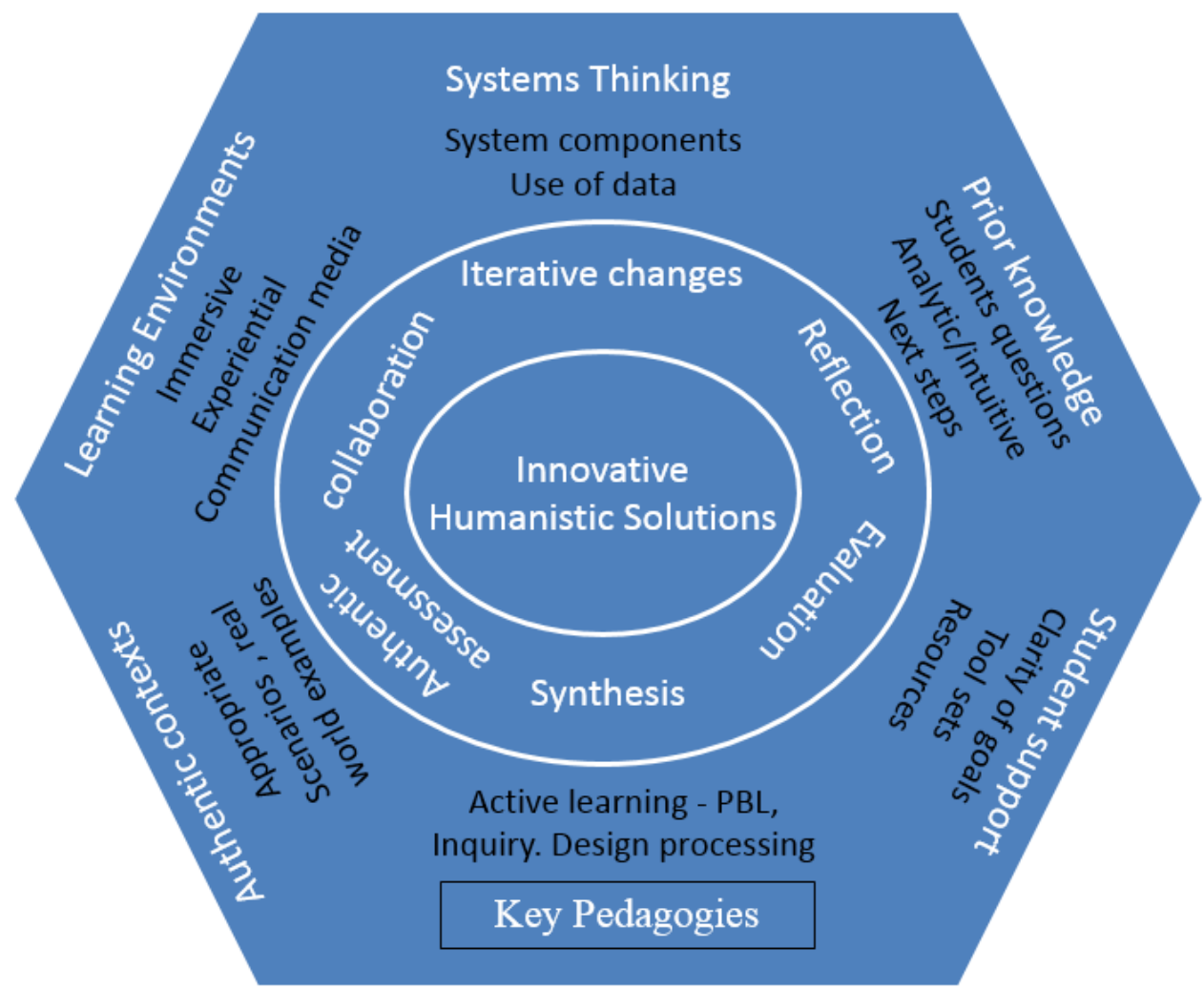

Figure 1. Framework for integrating STEMM in higher education

\section{References}

Association of American Universities (2012). AAU undergraduate STEM education initiative. https://www.aau.edu/education-community-impact/undergraduateeducation/undergraduate-stem-education-initiative-3. Accessed 6 April, 2020.

Bammer, G, (2017). Should we discipline interdisciplinarity? Palgrave Communications, 3 (30) DOI: 10.1057/s41599-017-0039-7

Bush, S. B. \& Cook, K. L. (2019). Structuring steam inquiries: lessons learned from practice. In M. S Khine \& S. Areepattamannil (eds.), Steam education: theory and practice, pp. 19-35. Cham: Springer Nature.

Conner, L. (2014) Students' use of evaluative constructivism: comparative degrees of intentional learning. International Journal of Qualitative Studies in Education, 27(4), 472-489. doi: 10.1080/09518398.2013.771228.

Corrigan, D., Buntting, C., Dillon, J., Gunstone, R. (Eds.). (2015). The future in learning science: what's in it for the learner? Cham: Springer International Publishing: imprint: Springer. 
Czerniak, C. N. (2007). Interdisciplinary science teaching. In S. K. Abell \& N. G. Lederman (Eds). Handbook on research on science education. (pp. 537-560). New York: Routledge.

Delanty, G. (2001). Challenging knowledge: The university in the knowledge society. Buckingham: Society for Research into Higher Education and Open University Press.

Honeybun-Arnolda, E. \& Obermeister, N. (2019). A Climate for Change: Millennials, Science and the Humanities, Environmental Communication, 13 (1), 18, DOI: $10.1080 / 17524032.2018 .1500927$

Malcolm, S. \& Feder, M. (Eds). (2016). Barriers and Opportunities for 2-Year and 4-Year STEM Degrees: Systemic change to support students' diverse pathways. Washington: The National Academies Press. Doi: 10.17226/21739

Miller, E. C. \& Krajcik, J. S. (2019). Promoting deep learning through project-based learning: a design problem. Disciplinary and Interdisciplinary Science Education Research, 1(7), Doi: 10.1186/s43031-019-0009-6

National Academies of Sciences, Engineering, and Medicine (2018). The integration of the humanities and arts with sciences, engineering, and medicine in higher education: branches from the same tree. Washington, DC: The National Academies Press. https://doi.org/10.17226/24988. Accessed 6 April, 2020.

Shaman, J., Solomon, S., Colwell, R. R., \& Field, B. (2018). Fostering advances in interdisciplinary climate science. Proceedings of the National Academy of Sciences, 110(1), 3653-3656. Doi: 10.1073/pnas.1301104110

Schreiner, L. A., Louis, M. C., \& Nelson, D. D. (Eds.). (2012). Thriving in transitions: a research-based approach to college students' success. Columbia: National Resource Centre for the first-year experience and students in transition.

Sniedze-Gregory, S. (2018). Enhancing interdisciplinary teaching and learning through guided assessment design (Unpublished PhD thesis). Flinders University, Adelaide, Australia.

World Economic Forum (2019). A global standard for lifelong learning and worker engagement to support advanced manufacturing.https:/www.weforum.org/whitepapers/ Accessed 6 April, 2020. 